\title{
A homossexualidade e a historiografia e trajetória do movimento homossexual
}

\section{Pluralized the art of love: homosexuality and historiography path of homosexual movement}

\author{
Luana Pagano Peres Molina ${ }^{1}$
}

RESUMO

Este artigo tem como objetivo compreender o desenvolvimento do movimento homossexual no Brasil, para entendermos assim, como este chega à atualidade, com a preocupação de discutir e criar programas que combatam a homofobia, principalmente debatendo questões que envolvam a diversidade sexual.

PALAVRAS-CHAVES: Homossexualidade. Homofobia. Movimento Homossexual.

\section{ABSTRACT}

This paper aims to understand the development of the homosexual movement in Brazil, to understand well, as it reaches to the present, with the aim to discuss and create programs that fight homophobia, especially debating issues involving sexual diversity.

KEY-WORD: Homosexuality. Homophobia. Homosexual Movement.

\section{Pluralizando sujeitos. Pluralizando a Arte de Amar}

Raça sobre a qual pesa a maldição e deve viver na mentira e no perjúrio, visto que sabe ser tido por punível e vergonhoso, por inconfessável, seu desejo, o que faz para toda criatura a maior doçura do viver.

Proust (1957)

Amar alguém do mesmo sexo, entregar-se à dor e à delícia de sentir-se apaixonado como em qualquer relacionamento no qual criamos laços de ternura, tornase mais difícil para os homossexuais, uma vez que os riscos do encontro e desencontro de amar alguém simbolizam romper com o mundo sociocultural que os indivíduos estão inseridos. Um mundo que esconde as diversas faces do amor e prega um discurso heterossexista, levando a maioria dos homossexuais a uma árdua luta por sua identidade, autonomia e direitos. Direitos como seres humanos. Direito ao amor.

1 Graduada em História e Professora Especialista em Psicologia Aplicada à Educação pela Universidade Estadual de Londrina. Mestranda em História Social, na linha de Ensino de História, pela UEL, bolsista da Capes, trabalhando com temas envolvendo temáticas referentes ao ensino de história, gênero e sexualidade. 
Ser homossexual, reconhecer-se homossexual, traz à tona a revolução dos tempos, sentimentos e sonhos de milhares de pessoas. Portanto, retrataremos uma pequena parcela dessa luta, que incansável, dedica-se a grande revolução do amor.

Ao trabalhar a homossexualidade inserida na nossa tradição ocidental judaicocristã, lidamos com uma temática que foi, e ainda é, de alguma maneira, vista e tratada como um pecado abominável, um crime, uma imoralidade. Segundo o antropólogo Luiz Mott (2003), a importância de estudar sobre a homossexualidade na realidade brasileira é ter a possibilidade de desvendar as raízes do preconceito em nossa sociedade, contribuindo para erradicar a intolerância e a crueldade contra os homossexuais.

Dentro da diversidade sexual, os grupos de gays, lésbicas, travestis e transexuais são vítimas de preconceitos e discriminações, devido a sua orientação sexual e à identidade de gênero. A homofobia, preconceito contra pessoas que se relacionam afetivo-sexualmente com outras do mesmo sexo, é diariamente marcada por gestos, olhares, palavras, discursos, agressões e até mesmo assassinatos, que Luiz Mott, em seu livro "Homossexualidade: Mitos e Verdades" retrata como um ódio doentio contra aqueles que ousam transgredir a ditadura heterossexista:

A este ódio mórbido contra a homossexualidade a Psicologia chama de homofobia internalizada, provocando nestes doentes, sintomas diversos, incluindo neurose de frustração sexual, suicídio e atos de violência, como agressões e assassinato sádico de homossexuais (MOTT, 2003).

Ao abraçar a luta para explicitar a homofobia velada e silenciosa, mas existente de maneira cruel, nas escolas e na nossa sociedade, pude abraçar também a possibilidade de entrelaçar histórias de vidas que sensivelmente nos encorajam a cada vez mais entender melhor a sexualidade e a diversidade sexual tão inerente às pessoas. Inerente a ponto de ser um direito humano inalienável, mas, devido à contradição social, mostra-nos ainda um direito inalcançável aos homossexuais.

A homossexualidade foi ao longo dos tempos e das diferentes culturas, motivo de punição, de vergonha, segregação e violência contra todos aqueles que atravessassem a fronteira da heteronormatividade2. Desta maneira, encontramos neste artigo, pontuações e contextualizações sobre a desconstrução do ser homossexual e pluralizando os discursos da identidade de gênero, para que possamos compreender a urgência das políticas identitárias e a ascensão do movimento homossexual.

2 Entendemos por heteronormatividade a obsessão com a sexualidade normatizante heterossexual, através de discursos que descrevem a situação homossexual como desviante e imoral. Colocando desta maneira, segundo Débora Britzman, uma imagem de identidade sexual heterossexual como "normal" e "natural". 
Rosa Maria R. Oliveira (2009) pontua a necessidade de trabalharmos o conceito de gênero de forma mais livre e menos rigorosa e, não como um lugar privilegiado nos conflitos sociais de maneira a assegurar uma reprodução social dentro da dicotomia homens/mulheres. As análises sociológicas das relações de Gênero, sustentadas pelos conceitos de papéis sexuais, desafiaram essa visão essencialista da biologia sobre as identidades humanas à medida que proporcionaram o questionamento referente à construção histórico-cultural das pessoas e à importância do meio sociocultural em sua formação. Assim:

O estudo de gênero e sua compreensão surgem pela forma como a cultura expressa as diferenças entre homens e mulheres e de que modo a caracterização das diferenças inerentes ou aprendidas entre os sexos pode servir como ponto auxiliar para compreensão da exclusão das pessoas que vivem a experiência homoerótica como entes capazes de direitos e obrigações (OLIVEIRA, 2009, p. 161).

Os sujeitos aprendem o conceito de status sexual, segundo essa autora, através dos comportamentos apropriados a esse status, ou seja, é dentro desta linha que se conceberá a masculinidade e a feminilidade, que se convertem em identidades psicológicas a cada pessoa. Portanto, a participação diversa dos homens e mulheres nas instituições sociais, econômicas, políticas e religiosas são marcadas pela identificação dos diferentes papéis sexuais, incluindo atitudes, valores e expectativas que uma dada sociedade conceitualiza como femininas ou masculinas.

Assim, ao dizer que as relações de gênero são construídas socialmente, isso implica dizer que, elas se dão de forma diferente de uma sociedade para outra e em épocas diferentes; ou seja, os sujeitos históricos têm suas relações fundamentadas por um padrão dominante no gênero como: homem/ mulher, provedor/ reprodutor, público/ privado, dominação/ submissão.

Segundo a historiadora J oan Scott, esse pensamento dicotômico e polarizado sobre os gêneros, nos faz pensar e representar as relações sociais dentro dessa lógica; Portanto, desconstruir a polaridade rígida dos gêneros implica em buscar os processos e as condições que estabeleceram os termos da polaridade.

Guacira Lopes Louro (1999, p. 34), seguindo a idéia de Joan Scott, ainda retrata que uma das conseqüências mais significativas da desconstrução dessa dicotomia residiria na possibilidade de se repensar as possibilidades existentes na compreensão das diferentes formas de masculinidade e feminilidade que se constituem socialmente. Incorporando essa discussão, ainda questiona que o rompimento dessa dicotomia poderá levantar problemáticas, como o conceito de heterossexualidade, 
tratando de mulheres e homens que vivem feminilidades e masculinidades de formas diversas e não hegemônicas.

Ao estudarmos sobre a homossexualidade e, consequentemente, a desconstrução dos papéis sexuais do feminino e masculino, devemos repensar a representação e os discursos de identidade, do conhecimento e do poder cultural que circulam no aparato do saber/poder na sociedade, para que possamos (re)analisar e (re)construir o discurso da própria sexualidade.

A autora Débora Britzman (1996) afirma que pensar a identidade significa não apenas ver esses elementos como efeitos constitutivos das relações sociais e da história, mas também como capazes de rearticular o desejo e o prazer. Quando se trata de questões de desejo, de amor e de afetividade, a identidade é capaz de surpreender a si mesma; de criar formas de sociabilidade, de política e de identificação que desvinculem o eu dos discursos dominantes da biologia, da natureza e da normalidade.

Nenhuma identidade sexual - mesmo a mais normativa - é automática, autêntica, facilmente assumida; Nenhuma identidade sexual existe sem negociação ou construção. Não existe, de um lado, uma identidade heterossexual lá fora, pronta, acabada, esperando para ser assumida e, de outro lado, uma identidade homossexual instável, que deve se virar sozinha. Em vez disso, toda identidade sexual é um construto instável, mutável e volátil, uma relação social contraditória e não finalizada (BRITZMAN, 1996, p. 74).

Ainda segundo essa teórica, os mitos criados acerca da homossexualidade, ao longo dos tempos, acabam por eficazmente produzir noções normativas que posicionam a heterossexualidade como sendo a sexualidade estável e natural, inviabilizando o sujeito homossexual de vivenciar com plenitude seus direitos como cidadãos, levando-os a um isolamento social e emocional. Assim entendemos que:

[...] A identidade heterossexual normativa exija que se construa, ao mesmo tempo, a homossexualidade como falta o que se deixa de pensar é que todas as sexualidades devem ser construídas, que nossas práticas e interesses são socialmente negociados durante toda nossa vida e que a moldagem sexual não precisa estar presa a estruturas de dominação e sujeição (BRITZMAN, 1996, p. 91).

O termo homossexualidade foi utilizado pela primeira vez pelo médico húngaro Karoly Maria Benkert em 1869. Segundo J effrey Weeks (1999), a afirmação do termo heterossexualidade foi possível devido à necessidade de definição da homossexualidade, desta forma, passando a assumir uma descrição médico-moral no século XIX, empreendida, pelo alemão Kraft-Ebing, como forma de especificar as identidades sexuais justamente no que se referia a seus tipos e formas. 
Segundo Neil Franco (2009), juntamente com a utilização do termo homossexualidade passou a existir o termo "uranista", cunhado pelo médico alemão Karl Heiring Urichs, uma vez que este termo remetia à musa Urânia, que de acordo com a mitologia contada por Platão, inspirava o amor entre pessoas do mesmo sexo.

No Brasil, o termo homossexualidade foi utilizado pela primeira vez em 1894 no livro: "Atentados ao pudor: estudos sobre as aberrações do instinto sexual" de Francisco J osé Viveiros de Castro, professor de Criminologia da Faculdade de Direito do Rio de Janeiro e desembargador da corte de Apelação do Distrito Federal, nos expõem o teórico J ames Green (2000).

Neil Franco explica que a homossexualidade passou a referir-se a uma pessoa distinta, tornando-se o oposto em relação à heterossexualidade após a consolidação das sociedades industrializadas ocidentais, o que não acontecia antes do século XIX. Desta forma, na segunda metade do século XX, os processos de industrialização, urbanização e desenvolvimento socioeconômico foram representativos na estruturação de identidades gays e lésbicas em diversas sociedades ocidentais, inclusive na brasileira.

Por isso a importância de atentarmos também ao processo na construção social do movimento homossexual e sobre de que maneira refletiu na construção da imagem, dos direitos e da luta para os homossexuais na sua abrangência históricosocial na metade do século XX para frente. Como vemos nesta fala de Richard Parker (2002):

Bem ou mal, foi dentro deste contexto - de desenvolvimento dependente, autoritarismo e redemocratização, capitalismo industrial e neoliberalismo no mundo moderno cada vez mais globalizado - que as vidas de homens e mulheres gays evoluíram no Brasil durante as últimas décadas. É nesse contexto que as esperanças, imaginações e esforços devem ser compreendidos.

Michele C. Conde (2004) refere-se aos movimentos sociais como sendo resultantes da necessidade de melhorias na existência de personagens descontentes com a maneira pela qual são percebidos e tratados pelas esferas públicas e pelas instituições (privadas ou não) e, em última instância, e de uma maneira difusa, pela sociedade. Se existe a necessidade de elaboração de estratégias e de articulações é porque existem opositores aos anseios desses atores à pugna desse movimento social. A autora descreve:

Ao trazer a discussão da sexualidade para o domínio público, assim como o fizeram o feminismo e os movimentos de liberação sexual da década de 1960, o movimento homossexual apresenta uma antinomia e exige que ela seja assumida pelo Estado laico de direito, distante dos dogmas religiosos e das noções preconcebidas - a sexualidade é 
política, e a individualidade constitui um direito humano fundamental. Em outras palavras, o movimento não admite que o desrespeito ao direito humano fundamental de exercer livremente a orientação sexual seja tratado pelo Estado como assunto limitado à esfera privada (CONDE, 2004, p. 15).

Reis (2007) pontua que as primeiras tentativas de organização de um movimento homossexual contra as discriminações e reivindicações de direitos foram ocasionadas na Europa, entre 1850 e 1993, como reação às legislações que criminalizavam atos sexuais entre pessoas do mesmo sexo. Outro momento foi na Alemanha de 1933, com o advento do regime nazista, no qual mais de 200 mil homossexuais foram mortos.

Será nos anos de 1960, no contexto de pós segunda - guerra, que se organizou o primeiro movimento GLBTT (Gays, Lésbicas, Bissexuais, Travestis e Transgêneros):

\begin{abstract}
A data que ficou como marca na história do moderno movimento gay mundial foi 28 de junho de 1969, quando a rebelião de GLBTT contra as arbitrárias batidas policiais no Bar Stonewall, em Nova Iorque. No primeiro aniversário da rebelião, 10 mil homossexuais, provenientes de todos os estados norte-americanos marcharam, sobre as ruas de Nova Iorque, demonstrando que estavam dispostos a seguir lutando pelos seus direito. Desde então ' 28 de J unho' é considerado o Dia Internacional do Orgulho GLBTT (REIS, 2007).
\end{abstract}

Sobre esse acontecimento, organizaram-se, em seguida, cinco dias de protestos contra a discriminação, exigindo a igualdade de direito aos homossexuais. Conforme relatado por Toni Reis, esse evento, nos Estados Unidos, impulsionou o mundo à visibilidade cultural e aos questionamentos referentes à homossexualidade.

Segundo o estudioso Anderson Ferrari (2004), foi na efervescência desse contexto, que os movimentos sociais sofreram a influência dos movimentos de contracultura inseridos pelo mundo afora, mas originários na Inglaterra e nos Estados Unidos. Sob esse aspecto, os grupos de militância gay buscavam elaborar novas formas de representação dos homossexuais para a sociedade, através de uma (re)construção na relação homossexualidade/sociedade e da construção de identidades mais positivas, embasadas na valorização da auto-estima, da auto-imagem e do auto-conceito de seus integrantes.

Na sociedade brasileira, foi no final da década de 1970 e no início de 1980, num contexto de regime militar, que os movimentos sociais marcam a história na busca não somente pela democracia, mas pela cidadania plena e pelos direitos civis. Essa visibilidade também é construída pelos movimentos gay. 
O fim da ditadura militar fazia surgir e reforçava um sentimento de otimismo cultural e social que atingia a todos. A abertura política possibilitava sonhar com uma sociedade mais democrática, igualitária e justa e, mais especificamente, trazia a esperança para o movimento gay de uma sociedade em que a homossexualidade poderá ser celebrada sem restrições (FERRARI, 2004, p. 105).

Esse período para o movimento homossexual ocorreu, principalmente, em decorrência da imprensa escrita no Brasil, com o jornal Lampião de Esquina, editado por um grupo de intelectuais homossexuais, publicado pela primeira vez em abril de 1978, na cidade do Rio de Janeiro - RJ a qual foi a primeira a apresentar-se como porta-voz do movimento, como afirma Conde (2004):

\begin{abstract}
Inicialmente, a proposta do jornal Lampião de Esquina consistia em tratar, de modo unificado, questões relativas às mulheres, aos negros, aos ecologistas e aos homossexuais e, muito embora tenha publicado diversas matérias relativas ao feminismo, como aborto e estupro, bem como ao lesbianismo, tendo sido até um dos promotores do movimento lésbico durante a sua existência, o jornal manteve seu foco predominantemente em assuntos relativos à homossexualidade masculina.
\end{abstract}

O primeiro movimento gay do Brasil surgiu, em São Paulo, em 1979 e o Primeiro Encontro Brasileiro de Homossexuais foi realizado em 1980. Segundo Tony Reis, logo após, formaram-se outros grupos e associações num momento de grande advento do vírus HIV 3 .

Desta maneira, fortalecendo-se frente à sociedade, os grupos e as associações voltadas à homossexualidade ganham visibilidade aproximando o Movimento Gay do Estado Nacional, por meio de políticas públicas voltados a contenção do vírus HIV. Anderson Ferrari pontua que a multiplicação dos movimentos gays organizados estaria evidenciando uma nova postura dos homossexuais e, consequentemente, uma nova relação entre cultura, sociedade e indivíduos. Esse seria um espaço de extrema importância na luta por direitos, por visibilidade, por emancipação, por justiça e principalmente por uma educação mais formal, com relação à AIDS, que em seu início atingiu, sobremaneira, a comunidade homossexual masculina.

Ante a exigência de se organizar contra a doença, os movimentos gays reafirmaram a importância da educação como a melhor arma nessa guerra sem tréguas, dando origem a diferentes cursos de prevenção de Doenças Sexualmente Transmissíveis (DST)/AIDS, assim como trabalhos e projetos de assistência a pessoas infectadas pelo HIV (FERRARI, 2004, p. 3).

3 Trata-se da síndrome de imunodeficiência adquirida (Sida), cuja sigla em inglês é Aids. 
A epidemia obrigou a sociedade a discutir sexualidade. Independentemente da forma como foi orientada a temática, ela passou a estar presente nas agendas e a ser preocupação para familiares, escolares e estatais. O surgimento da AIDS abriu espaço para a visibilidade homossexual, ainda que, tenham-se inicialmente refreado as tentativas de mobilizar setores do movimento. A doença foi também uma das principais responsáveis pela força com que esse movimento (re)emergiu na década de 1990.

Em 1995, em Curitiba, foi criada a ABGLT - Associação Brasileira de Gays, Lésbicas e Transgêneros, ocasionando um marco na organização e fortalecimento destes segmentos, proporcionando um rápido crescimento no número de grupos e redes que reivindicam a igualdade, assim como a visibilidade das paradas gays em busca de direitos e que desta maneira, atentassem a sociedade a ouvir a causa dos que por tanto anos foram e continuavam a ser marginalizados.

A primeira Parada do Orgulho GLBTT aconteceu na cidade de São Paulo em 1997, com a participação de duas mil pessoas. No ano de 2007, conforme informa Toni Reis, esta manifestação social foi considerada a maior do país, alcançando o número de um milhão e meio de pessoas.

O movimento objetiva a construção do sujeito, responsável pelas mudanças de visões, posturas, hábitos e transformação das pessoas a partir de um conhecimento de si e do mundo. De forma consciente, o movimento gay surgiu a partir de uma preocupação com o entendimento do mundo, com a tentativa de esclarecer e dominar os parâmetros de sua organização e de classificação da homossexualidade; e com a demanda de desconstruir as identidades homossexuais cristalizadas em busca de possibilidades de vivências mais positivas.

\section{Um Novo Sentido, Uma Nova Nomenclatura}

É opressivo libertar' as pessoas, se sua própria história e cultura não servem como fonte fundamental de definição de sua liberdade.

Sharon Welch

Diante das transformações ocorridas na sociedade e em sua cultura, no decorrer dos tempos, percebemos que se perpassaram para os movimentos sociais as alterações nas diversas formas de ideologias, pensamentos e questionamentos.

Assim como crescem e amadurecem as formas dos movimentos sociais, surgem novas interrogações e propostas para o universo homossexual, inclusive no que diz respeito a sua nomenclatura, ou seja, problematizando e pluralizando os discursos de identidade, criando nomenclaturas específicas para gays, lésbicas, bissexuais e transgêneros. 
Junto à efervescência e poder dos movimentos sociais, em um processo de construção e reconstrução de identidades sexuais e de gênero, surge, na metade dos anos 90, a sigla GLS (Gays, Lésbicas e Simpatizantes). Neste momento, a sigla GLS traduzia um discurso de convívio harmonioso e pluralista de diversas formas de identidade em um mesmo espaço físico ou ideológico (FRANCO, 2009, p. 65).

Porém, Trevisan (2007) nos aponta a critica mais freqüente em relação à adoção das identidades GLS, que acabava por enfatizar uma parte dos adeptos pela denominação simpatizantes, ficando restritos aqueles (as) que se identificavam como gays ou lésbicas. Desta maneira, o termo simpatizante atribuía a essas pessoas mais uma concepção ou ideia de enrustido (a), descaracterizando a luta política por uma visibilidade social.

Facchini (2005), em seu trabalho sobre o movimento homossexual na década de 1990, nos expõe que, no ano de 1998, por meio de intercâmbios de militantes do movimento homossexual brasileiro com os internacionais, adotou-se a sigla GLBT, no intuito de abranger a Gays, Lésbicas, Bissexuais e Transgêneros:

[...] a especificação de categorias como lésbicas, travestis e transexuais pode ser compreendido como escolhas, feita a partir de um leque de possibilidades - que com o incentivo da globalização e da grande circulação de informações, passam a trazer referências criadas em outros contextos culturais ou no âmbito de iniciativas de outra natureza, como a academia [...] Há um processo de resignificação e um contexto político- cultural local que permitem a demanda por novas categorias ou estilos e que influenciam a apropriação de determinada categoria ou estilo e não de outra (FACCHINI, 2005, p. 181).

Entende-se aqui a flexibilidade e a reflexividade possíveis perante a vivência afetivo-sexual de cada indivíduo. Desta maneira, assim como dentro do crescente movimento homossexual, somos confrontados com a necessidade de fazermos escolhas que nos colocam mais ou menos próximos de um estilo e/ ou padrão de vida, explicanos Facchini. O entendimento do cotidiano, das identidades e das diferenças como construção social, histórica e cultural parece contribuir para a elaboração de projetos de emancipação, que serão construídos no presente a partir dos inconformismos do passado e com a perspectiva do pensamento das opções do futuro.

Percebe-se, então, que muitos estudiosos e documentos oficiais utilizam esta nova nomenclatura de muitas maneiras diferenciadas, como: GLTB, GLBTT, LGTB, entre outros, de maneira que expressam a possibilidade de integração de outras

4 Nesta pontuação, cabe-se a terminologia Transgêneros, como meio de referir-se a duas categorias: Travestis e transexuais. 
identidades socais, a partir do momento em que pessoas se manifestem e exijam seu reconhecimento, pontua Neil Franco.

Em junho de 2008, na I Conferência Nacional de Políticas Públicas para GLBT foi impressa a discussão da mudança da sigla GLBT para LGBT, como já adotado no cenário internacional. Segundo Neil Franco, essa mudança ocorreu no intuito de reconhecer a atuação e privilegiar as identidades lésbicas como uma forma de reparação ou de reconhecimento do processo histórico de invisibilidade pelo qual foram submetidas. Segue abaixo um quadro realizado por esse autor, contendo um breve resumo sobre o desenvolvimento do movimento homossexual brasileiro.

\section{Quadro 1- Descrição Resumida do Movimento Homossexual Brasileiro}

\begin{tabular}{|l|l|}
\hline Anos 60 & - Organização entre homossexuais masculinos para socialização. \\
\hline Anos 70 & $\begin{array}{l}\text { - Primeiras formas de organização política entre homossexuais masculinos. - } \\
\text { Criação do Movimento Homossexual Brasileiro (MHB). }\end{array}$ \\
\hline 1979 & - Grupo Somos anuncia sua existência em debate na USP. \\
\hline 1980 & - Criação do Grupo de Ação Lésbico-Feminista. \\
\hline $1980 / 1992$ & - Realização de seis edições do Encontro Brasileiro de Homossexuais (EBHO). \\
\hline 1993 & $\begin{array}{l}\text { - Realização do VII Encontro Brasileiro de Lésbicas e Homossexuais. - } \\
\text { Realização do I Encontro Nacional de Travestis. - Criação do Festival de } \\
\text { Cinema GLS (Gays, Lésbicas e Simpatizantes). }\end{array}$ \\
\hline 1995 & $\begin{array}{l}\text { - Realização do VIII Encontro Brasileiro de Gays e Lésbicas. - Realização do I } \\
\text { Encontro Brasileiro de Gays e Lésbicas que trabalham com AIDS. - O } \\
\text { movimento torna-se Movimento de Gays e Lésbicas (MGL). }\end{array}$ \\
\hline 1997 & $\begin{array}{l}\text { - Realização do IX Encontro Brasileiro de Gays, Lésbicas e Travestis. - } \\
\text { RIDS. }\end{array}$ \\
\hline 1998 & $\begin{array}{l}\text { - Adequando-se ao movimento internacional, adota-se a sigla GLBT (Gays, } \\
\text { Lésbicas, Bissexuais eTransgêneros - Travestis eTransexuais). }\end{array}$ \\
\hline 2008 & $\begin{array}{l}\text { - Realização da I Conferência Nacional de Políticas Públicas para GLBT. - } \\
\text { Mudança da sigla para LGBT (Lésbicas, Gays, Bissexuais, Travestis e } \\
\text { Transexuais). }\end{array}$ \\
\hline
\end{tabular}

Fonte: Franco (2009, p. 67).

Atenta-se, conforme verificamos, a longa e expressiva luta por reconhecimento político e por visibilidade social desses diversos sujeitos ao longo da história e dos tempos.

Atualmente, percebemos uma ação mais diretamente voltada à diversidade sexual desencadeada pelo poder executivo federal, por meio do projeto Brasil sem Homofobia, Combate à Violência e à Discriminação contra GLTB e Promoção da Cidadania Homossexual 5 , em 24 de maio de 2004, coordenado pela Secretaria Especial de Direitos Humanos, atualmente ligados diretamente à Presidência da República.

5 Projeto disponível no site do Observatório Brasil da Igualdade de Gênero. Informações no site: $<$ www.observatoriodegenero.gov.br/ menu/ noticias/ brasilsemhomofobia>. 
O programa prevê onze ações, divididas em 53 itens e outros subitens e engloba a defesa à cidadania de homossexuais, por meio das seguintes ações:

- Articulação e fomento da política de promoção dos direitos de homossexuais;

- Legislação ejustiça;

- Cooperação internacional;

- Direito à segurança: combate à violência e à impunidade;

- Direito à educação, promovendo valores de respeito à paz e à nãodiscriminação por orientação sexual;

- Direito à saúde, consolidando atendimento e tratamentos igualitários;

- Direito ao trabalho, garantindo uma política de acesso e de promoção da não discriminação por orientação sexual;

- Direito à cultura, construindo uma política de cultura de paz e de valores de promoção da diversidade humana;

- Política para a juventude;

- Política para as mulheres;

- Política contra o racismo e a homofobia;

Ao longo desta jornada, o movimento social voltado às questões da diversidade sexual sofreu transformações a partir de rupturas e permanências na busca do exercício de cidadania e direitos humanos. No cenário nacional, um dos Programas mais importantes é o Brasil sem Homofobia do governo federal.

O objetivo da Educação sem Homofobia, aprovado em 2004, seria o de promover ações de combate ao preconceito, à discriminação e à violência referentes ao tema da homossexualidade e da transexualidade no centro do processo de formação de alunos e educadores, além de apontar para a importância da universidade para se repensar as práticas e as formas de ensino à luz dos direitos humanos e sexuais, possibilitando a capacitação de professores no intuito de levar esses novos conceitos ao universo escolar.

Esta iniciativa ocorreu uma vez que o índice de homofobia nas escolas tornouse alarmante, abrangendo a violência no cotidiano escolar e marginalizando pessoas que não vivem sua sexualidade de maneira heteronormativa. De acordo com Mello, Grossi e Uziel (2009), este programa começa a dar resultados e a se ampliar em níveis federal, estadual e municipal, com campanhas educativas com vistas a construir uma cultura de respeito à diversidade sexual em combate a homofobia.

Nesse Programa buscam serem aplicados seminários regionais temáticos, confecção de materiais para uso nas escolas e uma vasta pesquisa em mais de dez 
capitais brasileiras, onde cada vez mais pode-se afirmar que as escolas encaram os homossexuais como um problema e não, a homofobia. Por isso, ainda vivenciamos um período, no qual o ambiente escolar e sua equipe não sabem lidar com a diversidade sexual de seus alunos ou membros desta comunidade, como professores, diretores, pedagogos, etc. Resultando, desse fenômeno, uma grande porcentagem de evasão dos alunos por sentirem-se discriminados.

Outro ponto a deter-se, no desenvolvimento deste trabalho, é referente à terminologia orientação sexual e opção sexual. Hoje muitos estudiosos valem-se da terminologia orientação sexual por acreditarem que a homossexualidade não seria uma opção, mas sim um sentimento de desejo e amor. A escolha está implícita sim, mas somente quando decidimos nos relacionar ou não; contar ou não para a sociedade e família, enfrentar ou não os padrões sociais representativos da sociedade em que se está inserido. Porém seus sentimentos, a entrega, perceber a si próprio, apaixonar-se, é algo inerente a todo ser humano. Figueiró (2007, p. 29), nos diz:

\begin{abstract}
[...] homens e mulheres, quando começam a perceber que são homossexuais, sofrem, lutam contra esse sentimento, porque aprenderam, desde pequenos, que nossa sociedade aprova apenas o padrão de relacionamento homem-mulher. Sentindo-se "diferentes", sabem que terão que enfrentar dificuldades e temem perder o amor dos pais, dos irmãos, amigos [...] Se a homossexualidade fosse aprovada socialmente, tanto quanto a heterossexualidade, não haveria sofrimento em perceber-se uma pessoa homossexual. Ao invés de se falar em opção, o correto é dizer que a orientação da pessoa é homossexual.
\end{abstract}

Michele C. Conde também defende a ideia de opção significaria uma escolha que pode ou não ocorrer, ou seja, um livre arbítrio. Qualquer decisão tomada por livre arbítrio pode ser avaliada e julgada moralmente. Além disso, a previsão de nãodiscriminação em razão de sexo não se referia à discriminação por orientação sexual, já que se tratam de expressões distintas. Ainda segundo a autora, a discussão a esse termo foi iniciada pelo grupo Triângulo Rosa ${ }^{6}$, com base em correspondência enviada aos movimentos homossexuais então existentes no Brasil em 2002.

Desta maneira, entendemos que Orientação sexual refere-se ao sexo das pessoas que elegemos como objetos de desejo e afeto. Hoje, são reconhecidos três tipos de orientação sexual: a heterossexualidade (atração afetiva, sexual e erótica por pessoas de outro gênero); a homossexualidade (afetiva, sexual e erótica por pessoas

6 Movimento Homossexual, fundado no Rio de Janeiro na década de 1980 com o objetivo e estratégia voltados à obtenção de reconhecimento jurídico e político dos homossexuais. 
do mesmo gênero); e a bissexualidade (atração afetiva, sexual e erótica tanto por pessoas do mesmo gênero quanto pelo gênero oposto).

Portanto, acreditamos que, em vez de ver a questão da homossexualidade como sendo de interesse apenas para aquelas pessoas que são homossexuais, devemos considerar a forma como são construídos os discursos identitários dominantes da heterossexualidade que produzem seu próprio conjunto de ignorâncias, tanto sobre a homossexualidade quanto sobre a heterossexualidade, alimentando a homofobia e inviabilizando as possibilidades de sentimentos e experiências do sujeito no seu universo sexual.

A sexualidade está intrínseca à personalidade de todo ser humano. Seu desenvolvimento depende da satisfação de necessidades humanas básicas, como: desejo do contato, intimidade, expressão emocional, prazer, carinho, amor. Com isso, a sexualidade é construída por meio da interação entre os indivíduos e as estruturas sociais e seu total avanço é essencial para o desenvolvimento individual, interpessoal e social.

Por fim, todo o desenvolvimento histórico dos movimentos homossexuais, os estudos referentes à temática, as políticas públicas e a busca incessante pelo avanço de leis e direitos da população que abrangem toda a diversidade sexual, na sua construção de amor e amizade; mostra-nos uma luta incessante pelo fim da discriminação e do preconceito, ou seja, uma luta contra a tão arraigada homofobia presente, visível e invisivelmente, na nossa sociedade.

\section{Referências}

ASSOCIAÇÃO BRASILEIRA DE GAYS, LÉSBICAS E TRANSGÊNEROS. Resoluções do I Congresso da ABGLT: avanços e perspectivas. Curitiba, 2006.

BRASIL. Ministério da Educação. Secad. Instruções para Apresentação e Seleção de Projetos de Formação de Profissionais da Educação para a Promoção da Cultura de Reconhecimento da Diversidade Sexual e da Igualdade de Gênero. Brasília, 2006. Disponível em: <www.portal.mec.gov.br/ secad/ arquivos/pdf/ resumo.pdf>. Acesso em: 10 abr. 2011.

BRITZMAN, Deborah. O que é esta coisa chamada Amor - Identidade homossexual, educação e currículo. Revista Educação e Realidade, v. 21, p. 7196, jan/jun, 1996.

CONDE, Michelle Franco Conde. O Movimento Homossexual Brasileiro: sua trajetória e seu papel na ampliação do exercício da cidadania. 2004. Dissertação (Mestrado em Sociologia) - Universidade Federal de Goiás, Goiás, 2004. 
FACCHINI, Regina. Sopa de Letrinhas? O movimento homossexual e produção de identidades coletivas nos anos de 1990. Rio deJ aneiro: Garamond, 2005.

FERRARI, Anderson. Revisando o passado e construindo o presente: o movimento gay como espaço educativo. Revista Brasileira de Educação, v 25, p. 105-115, J an / Fev / Mar / Abr, 2004.

FIGUEIRÓ, Mary Neide Damico. Homossexualidade e Educação Sexual: Construindo o respeito à diversidade. Londrina: Ed. UEL. 2007.

FRANCO, Neil. A diversidade entra na escola: Histórias de professores e professoras que transitam pelas fronteiras das sexualidades e do gênero. 2009. Dissertação (Mestrado em Educação) - Universidade Federal de Uberlândia, Uberlândia, 2009.

GREEN, J ames N. Mais amor e mais tesão: A construção de um movimento de gays, lésbicas e travestis. Cadernos Pagu. Revista semestral do Núcleo de Estudos de Gênero - Pagu. Campinas, n. 15, 2000.

LOURO, Guacira Lopes (Org.).. Gênero, Sexualidade e Educação. Petrópolis: Ed. Vozes. 1999.

MELLO, Luiz; GROSSI, Miriam P; UZIEL, Anna Paula. As escolas e as filhas de lésbicas e gays: reflexões sobre conjugalidade e parentalidade no Brasil. In: J UNQUEIRA, Rogério Diniz (Org.). Diversidade sexual na educação: problematizações sobre homofobia nas escolas. Brasília: Ministério da Educação, 2009. p. 159-181.

MOTT, Luiz. Homossexualidade: mitos e verdades. Salvador: Ed. Grupo Gay da Bahia, 2003.

OLIVEIRA, Rosa Maria. Fronteiras Invisíveis: Gêneros, Questões identitárias e Relações entre movimento homossexual e Estado no Brasil. Revista Bagoas, n. 4, p. 160-172, 2009.

PARKER, Richard. Abaixo do Equador. Rio de J aneiro: Ed. Record, 2002.

REIS, Toni. O movimento homossexual. In: FIGUEIRO, Mary Neide Damico (Org.). Homossexualidade e educação sexual: construindo o respeito à diversidade. Londrina: EdUEL. 2007. p. 101-102.

TREVISAN, J oão Silvério. Devassos no Paraíso: a homossexualidade no Brasil, da colônia à atualidade. Rio de J aneiro: Ed. Record, 2007.

WEEKS, J effrey. O corpo e a sexualidade. In: LOURO, Guacira Lopes (Org.). O Corpo Educado: Pedagogias da sexualidade. Belo Horizonte: Autêntica, 1999. 